\title{
Relação entre a quantidade de AgNORS, atividade proliferativa e o estágio de desenvolvimento placentário em equinos ${ }^{1}$
}

\author{
Ana C.F. Mançanares ${ }^{2 *}$, Celina A.F. Mançanares ${ }^{3}$, André L.R. Franciolli ${ }^{2}$, Leandro O. Marques ${ }^{4}$, \\ Carlos E. Ambrósio ${ }^{3}$, Maria Angélica Miglino² e Ana Flávia de Carvalho ${ }^{5}$
}

\begin{abstract}
Mançanares A.C.F., Mançanares C.A.F., Franciolli A.L.R., Marques L.O., Ambrósio C.E., Miglino M.A. \& Carvalho A.F. 2012. [Relationship between the amount of AgNORs, proliferative activity and stage of placental development in horses.] Relação entre a quantidade de AgNORs, atividade proliferativa e o estágio de desenvolvimento placentário em equinos. Pesquisa Veterinária Brasileira 32(Supl.1):108-112. Programa de Pós-Graduação em Anatomia dos Animais Domésticos e Silvestres, Faculdade de Medicina Veterinária e Zootecnia, Universidade de São Paulo, Av. Prof. Dr. Orlando Marques de Paiva 87, Cidade Universitária, São Paulo, SP 05508-270, Brazil. E-mail: anamancanares@usp.br

The Nucleolar Organizer Regions (NORs - nucleolar organizer regions) are used to describe regions of chromatin stained with silver nitrate and are related to the activity of rRNA synthesis and to the agility and speed of cell proliferation in the tissues studied. The objective of this study was to relate the amount of AgNORs, proliferative activity and stage of pregnancy in horses, using the coloring of Silver Nitrate. The embryonic attachments were collected, fixed in $10 \%$ buffered formaldehyde, embedded in paraplast and stained by silver nitrate. The groups were determined according to the gestational age. The amount of the corium NOR found in early pregnancy indicates the onset of cell activity, and in that the pregnancy progresses, the amount of NOR increases, suggesting higher activity and increased synthesis of their importance in maintaining the fetus. Contrary to what occurs in the corium, the quantification of NORs was higher in late pregnancy than in the beginning, suggesting the stabilization of these membranes in late pregnancy. The chorionic girdle and the yolk sac were found in early pregnancy and had lots of NORs, suggesting synthesis function and proliferation in early pregnancy, since their functions is maintenance of the embryo until the complete formation of the true placenta (chorio-allantoic membranes). We conclude that the membranes that develop in a progressive manner in accordance with the growing embryo/fetal (chorion, amnion and allantoic membranes) have an increased number of NORs and the membranes that involute after the formation of the embryo/fetus (yolk sac and chorionic girdle) have a decrease in number, suggesting a reduction in proliferative activity in these membranes.
\end{abstract}

INDEX TERMS: Cell proliferation, AgNORs, nucleolus, placenta, equidae.

RESUMO.- As Regiões Organizadoras de Nucléolo (NORs nucleolar organizer regions) são utilizadas para descrever regiões de cromatina coradas por Nitrato de Prata e estão relacionados com a atividade de síntese de RNAr e com a

\footnotetext{
${ }^{1}$ Recebido em 20 de julho de 2012.

Aceito para publicação em 9 de novembro de 2012.

${ }^{2}$ Programa de Pós-Graduação em Anatomia dos Animais Domésticos e Silvestres, Faculdade de Medicina Veterinária e Zootecnia (FMVZ), Universidade de São Paulo (USP), Av. Prof. Dr. Orlando Marques de Paiva 87, Cidade Universitária, São Paulo, SP 05508-270, Brasil. *Autor para correspondência: anamancanares@usp.br

${ }^{3}$ Faculdade de Zootecnia e Engenharia de Alimentos, USP, Campus Pi-
}

agilidade e rapidez na proliferação celular nos tecidos estudados. 0 objetivo deste trabalho foi relacionar a quantidade de AgNORs, a atividade proliferativa e o estágio da gestação em equinos, utilizando a coloração de Nitrato de

\footnotetext{
rassununga, Av. Duque de Caxias Norte 225, Pirassununga, SP 13635-900, Brasil.

${ }^{4}$ Museu de Ciências Naturais, PUC Minas, Av. Dom José Gaspar 500, Coração Eucarístico, Campus PUC Minas, Belo Horizonte, MG 30535-901, Brasil.

${ }^{5}$ Centro Universitário, Fundação de Ensino Octávio Bastos (Unifeob), Avenida Dr. Octávio Bastos s/n, Jardim Nova São João, São João da Boa Vista, SP 13870-000, Brasil.
} 
Prata. Os anexos embrionários foram coletados, fixados em solução de formaldeído tamponado $10 \%$, emblocadas em paraplast e submetidos à coloração de Nitrato de Prata. Os grupos foram determinados de acordo com a idade gestacional. A quantidade de NORs encontrada no cório no começo da gestação indica início da atividade celular e na medida em que a gestação avança, a quantidade de NORs aumenta, sugerindo maior atividade de síntese e aumento da sua importância na manutenção do feto. Ao contrário do que ocorre no cório, a quantificação das NORs foram maiores no final da gestação do que no inicio, sugerindo a estabilização destas membranas no final da gestação. A cinta coriônica e o saco vitelino foram encontrados no início da gestação e apresentaram grande quantidade de NORs, sugerindo função de síntese e proliferação no inicio da gestação, visto que suas funções é manutenção do embrião até a formação completa da placenta verdadeira (cório-alantoide). Concluímos que as membranas que se desenvolvem de maneira progressiva de acordo com o crescimento embrionário/fetal (cório, alantoide e âmnio) têm aumento no número de NORs e as membranas que involuem após a formação do embrião/feto (saco vitelino e cinta coriônica) têm um decréscimo neste número, sugerindo a diminuição da atividade proliferativa nestas membranas.

TERMOS DE INDEXAÇÃO: Proliferação celular, AgNORs, nucléolo, placenta, equinos.

\section{INTRODUÇÃO}

As Regiões Organizadoras de Nucléolos ou NORs (do inglês, "nucleolar organizer regions") são utilizadas para descrever regiões constituídas de fragmentos de cromossomos que formam os nucléolos no final da mitose. Estas regiões correspondem a alças do DNA contendo genes responsáveis pela transcrição do RNA ribossômico, situados no nucléolo da célula (Gall \&Pardue 1969), e estão relacionados com a atividade de síntese de RNAr e com a agilidade e rapidez na proliferação celular nos tecidos estudados (Derenzini \& Ploton 1991).

Diversos métodos para a coloração por nitrato de prata já foram estabelecidos, de acordo com o tipo de fixação e o tipo de tecido a se analisado. São identificadas através da coloração por nitrato de prata, onde pontos escuros na área nucleolar são corados (Crocker \& Egan 1988, Egan \& Crocker 1988, Soomro et al. 1988, Whimster 1991, Trere 2000).

A quantificação das AgNORs é simples em relação às demais técnicas e tem sido amplamente utilizada em morfometria quantitativa, como método auxiliar na distinção entre células benignas e malignas, em diversos tecidos (Serakides et al. 1999, Kruger et al. 2000, Pich et al. 2000).

0 objetivo do trabalho foi determinar a relação entre a quantidade de AgNORs, a atividade celular e o estágio da gestação utilizando marcadores em placentas equinas, a fim de evidenciar a atividade metabólica das células das membranas embrionárias e fetais, estabelecendo assim um padrão de normalidade para gestações equinas, para que no futuro possamos comparar com estações anormais ou provenientes de embriões manipulados em laboratório.

\section{MATERIAL E MÉTODOS}

Foram utilizadas 30 amostras de placentas de éguas adultas, sem raça definida, do primeiro ao terceiro trimestre de gestação, proveniente do frigorífico Miramar, Pelotas - Rio Grande do Sul.

A idade fetal foi estimada baseada na mensuração da distância do ponto maior da cabeça até a última vértebra sacral, na extremidade oposta (CR - Crown-rump) e separada em grupos (Quadro 1) (Evans \& Sack 1973).

Quadro 1. Grupos de embriões divididos de acordo com Crown-Rump mensurado (São Paulo, 2012)

\begin{tabular}{cccc}
\hline Grupo & Número $(\mathrm{n})$ & Idade em dias & Comprimento da coluna $(\mathrm{cm})$ \\
\hline I & 8 & 15 a 47 & 2,0 a 4,9 \\
II & 8 & 53 a 57 & 5,0 a 7,9 \\
III & 7 & 71 a 88 & 8,0 a 14,9 \\
IV & 7 & 96 a 107 & 15,0 a 22,0
\end{tabular}

Os anexos embrionários foram coletados, fixados em solução de formaldeído tamponado 10\%, emblocados em paraplast e cortes de cinco micrômetros de espessura foram obtidos utilizando-se micrótomo (Leika, German) e submetidos à coloração de AgNOR.

Para a quantificação das AgNORs, as lâminas foram incubadas em solução final 1:2, que consiste de solução coloidal (1g de gelatina, $50 \mathrm{ml}$ de água deionizada e $0,5 \mathrm{~g}$ de ácido fórmico) e solução de nitrato de prata $1: 1$ (5g de $\mathrm{AgNO}_{3}$ e $5 \mathrm{ml}$ de água deionizada) levadas à estufa a $37^{\circ} \mathrm{C}$, em câmara úmida, por aproximadamente 20 minutos. Após a lavagem das lâminas com água destilada, aplicou-se solução de tiossulfato de sódio $1 \%$ por um minuto e procedeu-se a lavagem. Em seguida, as lâminas foram secas em temperatura ambiente e acondicionadas na ausência de luz.

A contagem das NORs foi feita a cada 100 células evidenciando a quantidade de NORs em cada célula e sua somatória final. A média e o desvio padrão do número total de AgNORs por célula em cada membrana foi determinada. Diferenças nas médias de AgNORs entre as amostras e entre os grupos gestacionais foram analisadas através do Anova seguida de Tukey para as membranas âmnio, alantoide e cório; e Teste F saco vitelino e cinta coriônica. Um valor de $\mathrm{p}<5 \%$ foi considerado significante.

\section{RESULTADOS}

A coloração por nitrato de prata (AgNORs) permitiu, através da microscopia de luz, a visualização de pequenos pontos escuros intranucleares, marcados pelas proteínas associadas as NORs (Nucleolar Organizer Regions)(Fig.1).

A contagem de NORs no âmnio no início da gestação (grupos GI e GII) apresentou média variando de 125,4 \pm 7 , 55 a $139 \pm 6,37$. Foi observado que nos grupos de meio e final de gestação (GIII e GIV), apresentam maior quantidade de NORs do que nos outros grupos, sendo seus valores respectivos $224,2 \pm 5,16$ e 136,2 $\pm 5,16$ (Quadro 2).

0 alantoide é a membrana com menor atividade de síntese e proliferação nestes grupos. Os grupos GI e GII apresentaram média de $122,6 \pm 8,33$ e $138 \pm 8,16$, respectivamente. No grupo, há um aumento no número de NORs $198 \pm 16$ e no GIV houve redução respectivamente 117,75 $\pm 4,81$ (Quadro 2).

No cório, a média obtida nos grupos GI e GII foram de $161,2 \pm 7,13$ e $177 \pm 47,02$, respectivamente. Nos grupos GIII e GIV houve um aumento na quantidade de AgNORs $(239,8 \pm 48,02$ e $225,75 \pm 13,23$, respectivamente) (Quadro 2). 

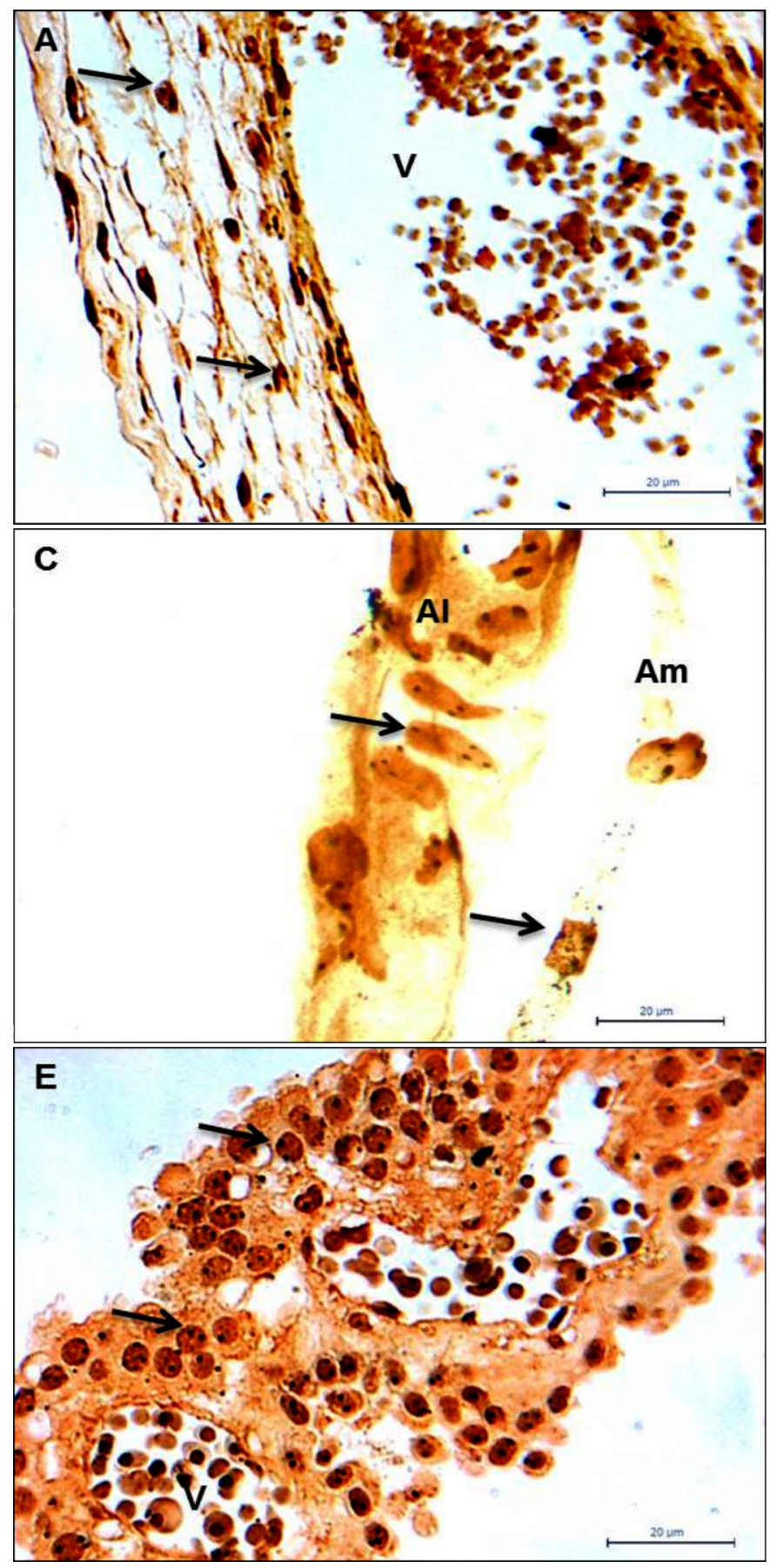

Quadro 2. Média e desvio padrão do número de NORs nas diferentes regiões e grupos analisados (São Paulo, 2012)

\begin{tabular}{lcccc}
\hline & GI & GII & GIII & GIV \\
\hline Âmnio & $125 \pm 7,55^{\mathrm{a}}$ & $139 \pm 6,37^{\mathrm{b}, \mathrm{c}}$ & $224 \pm 5,16^{\mathrm{b}}$ & $136 \pm 5,16^{\mathrm{c}}$ \\
Alantoide & $122 \pm 8,33^{\mathrm{a}}$ & $138 \pm 8,16^{\mathrm{b}}$ & $198 \pm 16^{\mathrm{b}}$ & $117 \pm 4,81^{\mathrm{c}}$ \\
Cório & $161 \pm 7,13^{\mathrm{a}}$ & $177 \pm 47,02^{\mathrm{b}, \mathrm{c}}$ & $239 \pm 48,02^{\mathrm{d}}$ & $225 \pm 13,23^{\mathrm{b}}$
\end{tabular}

$\overline{\mathrm{a}, \mathrm{b}, \mathrm{c}, \mathrm{d}}$ Médias com letras iguais na mesma linha, são iguais ao nível de $5 \%$ de significância pelo teste de Tukey.

A cinta coriônica expressou média de 219,2 $\pm 10,34$ e 203,6 $\pm 5,24$, nos grupos GI e GII de respectivamente (Quadro 3). À medida que a gestação evolui, notou-se o desaparecimento desta estrutura, exercendo assim sua
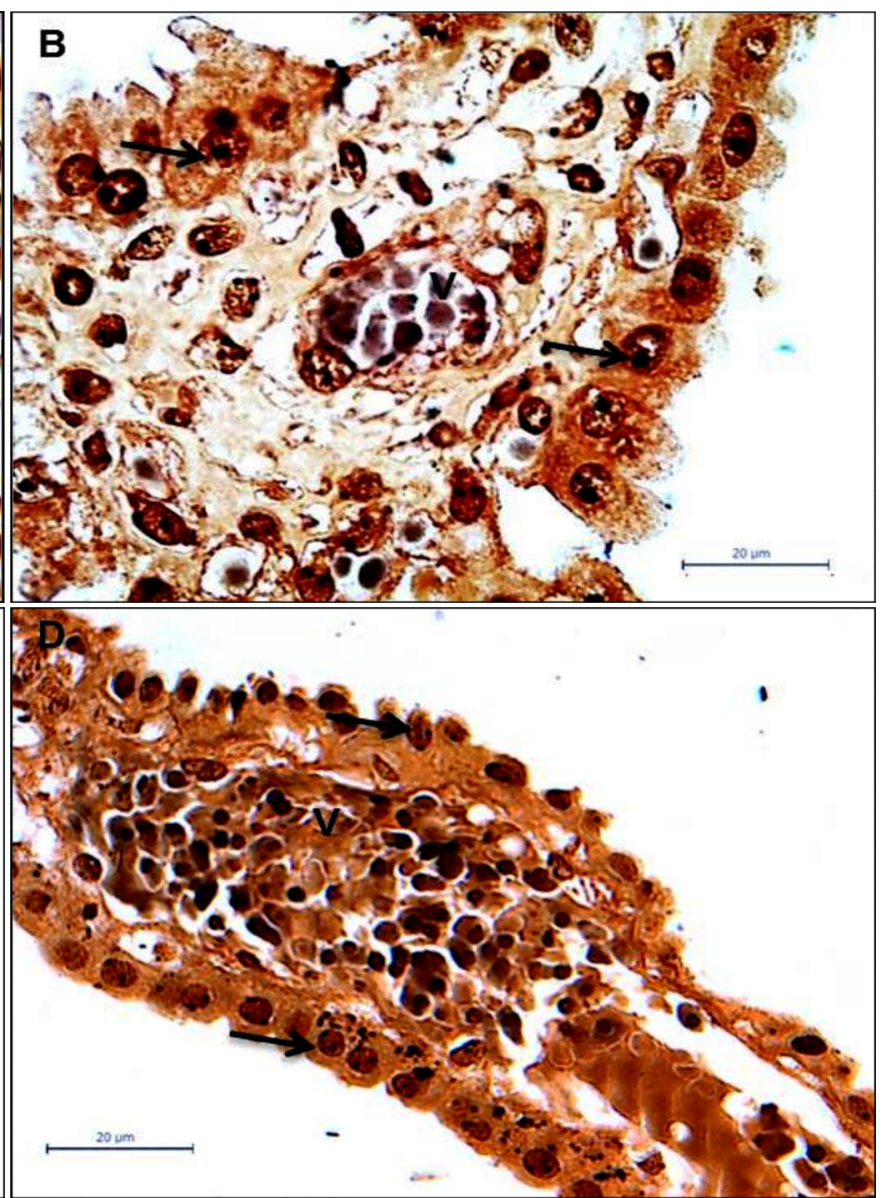

Fig.1. Membranas embrionárias e fetais de equino. Notar as regiões organizadoras de nucléolos (NOR) marcados pela coloração de Prata (seta) e vasos sanguíneos (V). (A) Al = alantoide. (B) $\mathrm{Co}=$ cório. (C) $\mathrm{Al}=$ alantoide, $\mathrm{Am}=$ âmnio. (D) $\mathrm{Sv}=\mathrm{Saco}$ vitelino. (E) Cc $=$ Cinta coriônica. Barra: $20 \mu \mathrm{m}$.

Quadro 3. Média e desvio padrão do número de NORs nas diferentes regiões e grupos analisados (São Paulo, 2012)

\begin{tabular}{lcc}
\hline & GI & GII \\
\hline Saco vitelino & $207 \pm 5,12^{\mathrm{a}}$ & $193 \pm 12,28^{\mathrm{b}}$ \\
Cinta coriônica & $219 \pm 10,34^{\mathrm{a}}$ & $203 \pm 5,24^{\mathrm{a}}$
\end{tabular}

a,b Médias com letras iguais na mesma linha, são iguais ao nível de 5\% de significância pelo teste $\mathrm{F}$.

função de síntese e proliferação somente no inicio da gestação.

A membrana com maior atividade de síntese no inicio da gestação foi o saco vitelino. Os grupos GI e GII apresentaram médias de $207,4 \pm 5,12$ e no grupo GII $193,3 \pm 12,28$ (Quadro 3). Assim como a cinta coriônica, o saco vitelino desaparece nos primeiros meses de gestação. Sua principal função é a manutenção do embrião até a formação completa da placenta verdadeira (cório-alantoide).

A membrana amniótica (Fig.1C), alantoide (Fig.1A) e cório (Fig.1B) são encontradas em todos os grupos estudados. Em contra partida, o saco vitelino (Fig.1D) e cinta coriônica (Fig.1E) involuem após a idade média de 60 dias de gestação, por isso não aparecem nos grupos GIII e GIV. 
A Figura 2 representa todas as membranas embrionárias e fetais, comparando o número de NORs nas diferentes fases de gestação, evidenciando assim a grande atividade das membranas coriônica, amniótica e alantoideana até GIV, com pico em GIII e grande atividade da membrana vitelina e região da cinta coriônica no inicio da gestação, com picos em GI e GII.

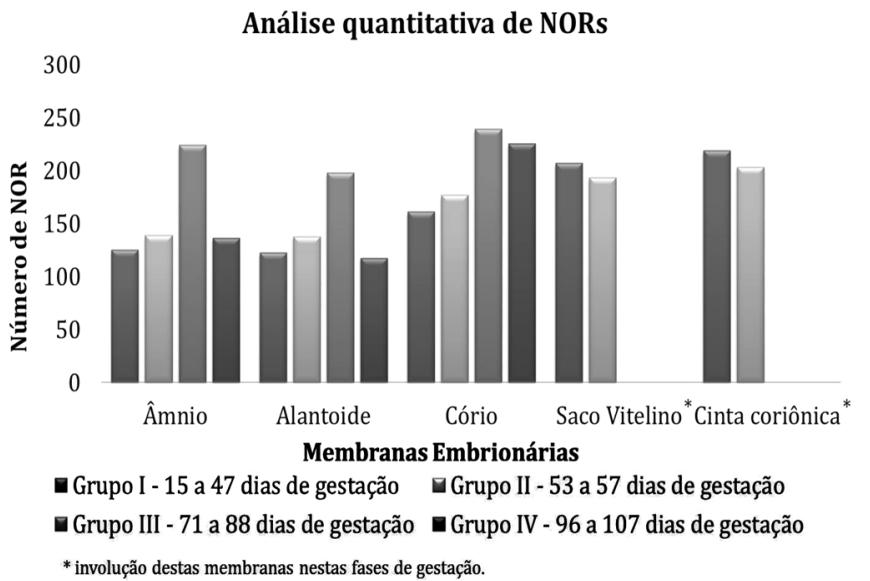

Fig.2. Comparação entre a quantidade média de AgNORs nas membranas embrionárias ao longo da gestação.

\section{DISCUSSÃO}

A técnica de AgNOR é simples, de fácil interpretação e pode ser utilizada como marcador de proliferação celular (Derenzini 1989, Trere 1989, Cabrini et al. 1992).

Por meio da microscopia de luz, visualizaram-se pequenos pontos escuros intranucleares (dots), que podem apresentar número, forma e tamanhos variados, permitindo uma análise quantitativa, qualitativa morfológica ou morfométrica dos mesmos.

Cada ponto corado pela prata corresponde ultraestruturalmente, ao centro fibrilar em íntima associação ao componente fibrilar denso (Derenzini et al. 1990, Derenzini \& Ploton 1991) e os mesmos foram facilmente evidenciados em todas as fases de prenhez em que se procedeu este estudo.

Muitos trabalhos demonstram que a quantidade de AgNORs representa um parâmetro válido para a cinética celular, significativamente associado com a agilidade de duplicação celular (Derenzini et al. 1989, 1990, Trere et al. 1989).

Assim como em nossos estudos, em tecidos placentários normais, a técnica de AgNORs exibiu um padrão entre a quantificação e o estágio da gestação. As células trofoblásticas da região inter-placentomal, apresentam maior número de AgNORs, sugerindo uma maior atividade proliferativa dessas células no final da prenhez (Rici et al. 2011).

Nossos estudos confirmaram o aumento da quantidade de AgNORs nas células a medida em que a prenhez avançou em algumas membranas como cório, âmnio e alantoide, indicando um aumento na atividade proliferativa e/ou metabólica dessas células. No saco vitelino e na cinta coriônica, apresentaram diminuição na quantidade de AgNORs no saco vitelino e na cinta coriônica, sugerindo a importância dessas estruturas no início da gestação e que posteriormente perdem a funcionalidade a medida em que o processo gestacional avança (Evans \& Sack 1973, Ferrel et al. 1976, Hinman 1976, Mançanares 2007).

A relação entre a quantidade de AgNORs e a duplicação celular pode ser explicada considerando que as células em proliferação precisam produzir um complemento ribossomal adequado para as células filhas. Considerando que o número de AgNORs está estritamente relacionado com a atividade transcricional do RNAr, sendo uma consequência lógica relacionada também a quantidade de AgNORs com células em duplicação (Derenzini 2000).

Além disso, considerando que essas células são responsáveis pela produção de diversos hormônios e fatores de crescimento associados ao desenvolvimento e manutenção da gestação (Schlafer et al. 2000), é natural que sua atividade metabólica aumente à medida que o concepto passa a requerer maior demanda nutricional. Sendo assim, a função placentária deve aumentar proporcionalmente para acompanhar o crescimento fetal (Ferrel et al. 1976).

\section{CONCLUSÕES}

Foi possível estabelecer uma relação entre o número de NORs expressas nas células com o estágio de gestação a que pertence o tecido avaliado e também com o nível de atividade metabólica dessas células.

As membranas que se desenvolvem de maneira progressiva de acordo com o crescimento embrionário/fetal (cório, alantoide e âmnio) têm aumento no número de NORs e as estruturas que involuem após a formação do embrião/feto (saco vitelino e cinta coriônica) têm um decréscimo neste número.

\section{REFERÊNCIAS}

Aubele M., Biesterfeld S., Derenzini M., Hufnagl P., Martin H., Ofner D., Ploton D. \& Ruschoff J. 1994. Guidelines of AgNOR quantitation. Committee on AgNOR Quantitation within the European Society of Pathology. Zentralbl. Pathol. 140(1):107-108.

Cabrin R.L., Schwint A.E., Mendez A., Femopase F., Lanfranchi H. \& Itoiz M.E. 1992. Morphometric study of nucleolar organizer regions in human oral normal mucosa, papilloma and squamous cell carcinoma. J. Oral Pathol. Med. 21(6):275-279.

Crocker J. \& Egan M.J. 1988. Correlation between nor sizes and numbers in non-Hodgkins lymphomas. J. Pathol. 156(3):233-239.

Derenzini M., Pession A., Farabegoli F., Trere D., Badiali M. \& Dehan P. 1989. Relationship between interphasic nucleolar organizer regions and growth -rate in 2 neuro-blastoma cell-lines. Am. J. Pathol. 134(4):925-932.

Derenzini M., Pession A. \& Trere D. 1990. Quantity of nucleolar silver-stained proteins is related to proliferating activity in cancer-cells. Lab. Invest. 63(1):137-140.

Derenzini M. \& Ploton D. 1991. Interphase nucleolar organizer regions in cancer-cells. Int. Rev. Exp. Pathol. 32:149-192.

Derenzini M. 2000. The AgNORs. Micron 31(2):117-120.

Egan M.J. \& Crocker J. 1988. Nucleolar organizer regions in cutaneous tumors. J. Pathol. 154(3):247-253.

Evans H.E. \& Sack W. O. 1973. Prenatal development of domestic and laboratory mammals: growth curves, external features and selected references. Zentralbl. Veterinärmed. C 2(1):11-45.

Ferrell C.L., Garrett W.N. \& Hinman N. 1976. Estimation of body-composition in pregnant and non-pregnant heifers. J. Anim. Sci. 42(5):11581166.

Gall J.G. \& Pardue M.L. 1969. Formation and detection of RNA-DNA hy- 
brid molecules in cytological preparations. Proc. Natl Acad. Sci. USA 63(2):378-383.

Kruger S., Stahlhut M. \& Muller H. 2000. Cell cycle-dependent AgNOR analysis in invasive breast cancer. Anal. Quant. Cytol. Histol. 22(5):358-363.

Mançanares C.A. F. 2007. Análise morfológica da área de transição do intestino primitivo para o saco vitelino em embriões e fetos bovinos (24 a 50 dias de gestação). Tese de Doutorado, área de Anatomia dos Animais Domésticos e Silvestres, Faculdade de Medicina Veterinária e Zootecnia, Universidade de São Paulo, São Paulo, SP. 115p.

Pich A., Chiusa L. \& Margaria E. 2000. Prognostic relevance of AgNORs in tumor pathology. Micron 31(2):133-141.

Rici R.E.G., Facciotti P.R., Franciolli A.L.R., Mançanares A.C.F., Pastori J., Maria D.A. \& Miglino M.A. 2011. Análise proliferativa nas células trofoblásticas em bovinos. Pesq. Vet. Bras. 31:538-542.
Schlafer D.H., Fisher P.J. \& Davies C.J. 2000. The bovine placenta before and after birth: placental development and function in health and disease. Anim. Reprod. Sci. 60:145-160.

Serakides R., Nunes V.A., Santos R.L., Cassali G.D. \& Costa Neto P.P. 1999. Histomorphometry and quantification of nucleolar organizer regions in bovine thyroid containing methylthiouracil residues. Vet. Pathol. 36(6):574-582.

Soomro I., Patel N. \& Whimster W.F. 1991. Distribution and estimation of nucleolar organizer regions in various human lung-tumors. Pathol. Res. Pract. 187(1):68-72.

Trere D., Pession A. \& Derenzini M. 1989. The silver-stained proteins of interphasic nucleolar organizer regions as a parameter of cell duplication rate. Exp. Cell Res. 184(1):131-137.

Trere D. 2000. AgNOR staining and quantification. Micron 31(2):127-131. 